Simone de Pinho Barbosa

Taniza Soares Elizeu ${ }^{2}$

Cláudia Maria Mattos Penna ${ }^{3}$

${ }^{1}$ Centro Universitário do Leste de Minas Gerais. Av. Dr. Raimundo Monteiro Rezende, Centro. 35.010-177 Governador Valadares MG. sidepinho@gmail.com ${ }^{2}$ Curso de Enfermagem, Centro Universitário Católico do Leste de Minas Gerais.

${ }^{3}$ Escola de Enfermagem, Universidade Federal de Minas Gerais.

\section{Ótica dos profissionais de saúde sobre o acesso à atenção primária à saúde}

\author{
The perspective of health professionals \\ on access to Primary Health Care
}

Abstract The term access is understood from the perspective of admission or entry into the system, related to the use of the system. This research seeks to analyze access to primary health care from the perspective of professionals in family health teams of three municipalities in the State of Minas Gerais: Ipatinga, Coronel Fabriciano and Santana do Paraíso. This work is a qualitative case study into the understanding of access on the part of professionals in family health teams. Twelve health professionals from different professional categories participated in the study. The data was collected through taped and subsequently transcribed interviews and analyzed using Bardin's content anal$y$ sis technique. As a result the professionals showed that they believe that it is possible to improve working conditions and consequently the supply of services. The type of care and the inherent complexity make a difference in waiting time and the ability of the system to respond thereby impacting the quality of access. Professionals in the municipalities of Coronel Fabriciano and Santana do Paraíso consider the service to be organized and decisive. However, in the municipality of Jaipur, there is high management turnover that hampers the organization of the service and the smooth operation of flows and routines.

Key words Access, Primary Health Care, Professionals
Resumo O termo acesso é compreendido na perspectiva do ingresso ou entrada no sistema, relacionado à utilização do mesmo. A pesquisa tem como objetivo analisar o acesso a partir da atenção primária à saúde na perspectiva dos profissionais de equipes de saúde da família de três municípios do Estado de Minas Gerais, Ipatinga, Coronel Fabriciano e Santana do Paraíso. Trata-se de um estudo de caso, qualitativo, sobre o entendimento a respeito do acesso por parte de profissionais de equipes de saúde da Família. Participaram da pesquisa 12 profissionais de saúde de diferentes categorias profissionais, a coleta de dados ocorreu por meio de entrevistas gravadas e posteriormente transcritas e analisadas pela técnica de análise de conteúdo de Bardin. Como resultado os profissionais demonstraram acreditar que é possivel melhorar as condições de trabalho e consequentemente da oferta de serviços. O tipo de atendimento e sua complexidade fazem a diferença no tempo de espera e na capacidade de resposta do sistema implicando na qualidade do acesso. Os profissionais dos municípios de Coronel Fabriciano e Santana do Paraíso consideram o serviço organizado e resolutivo, já no município de Ipatinga, existe uma rotatividade de gestão e gerenciamento que dificulta a organização do serviço e o estabelecimento de fluxos e rotinas.

Palavras-chave Acesso, Atenção Primária a Saúde, Profissionais 


\section{Introdução}

A Atenção Primária a Saúde (APS) no Brasil se configura como nível de atenção, onde se é capaz de detectar as reais necessidades e problemas de uma população, fornecendo respostas para as condições de uma comunidade e determinando o trabalho de todos os outros níveis dos sistemas de saúde.

A APS assume a lógica da organização da assistência à saúde em redes (RAS) compartilhando a capacidade de resposta do sistema de saúde, a responsabilidade pelo acesso, qualidade e custos, atenção à promoção da saúde, bem como ao tratamento e à reabilitação de doenças, que deve ser realizado pelo trabalho em equipe. Ao estar mais próxima da população atendida a APS aborda os problemas mais singulares de uma comunidade, oferecendo serviços de prevenção, cura e reabilitação apropriados às demandas de alcance ao bem-estar. É a atenção que estabelece e racionaliza o uso de todos os recursos, tanto básicos como especializados, direcionados para a promoção, manutenção e melhora da saúde ${ }^{1}$.

Este estudo representa um recorte de uma tese de doutorado realizada na Universidade $\mathrm{Fe}$ deral de Minas Gerais sobre o acesso e a resolutividade dos serviços de saúde pública na perspectiva dos profissionais e usuários de três municípios do Estado de Minas Gerais.

Travassos e Martins ${ }^{2}$ afirmam que a utilização de serviços pode ter impacto negativo, se ele não estiver aliado à qualidade dos cuidados ou procedimentos eficazes. Por mais acesso que se possa ter aos serviços, por mais que se possa planejar e organizar a saúde, por mais modelos de assistência que se implemente, a execução direta do atendimento vai além da técnica, ou seja, a sinergia do corpo a corpo entre profissionais e as pessoas que buscam o serviço se coloca como um dos determinantes desse processo.

No atual estágio de desenvolvimento do sistema de saúde brasileiro, já em um avançado processo de descentralização, observa-se uma crescente expansão de modelos de saúde centrados na APS, compreendida esta como a principal "porta de entrada” do sistema de saúde pública; e está representada desde 1994 pela Estratégia de Saúde da Família (ESF) como um espaço privilegiado para sua operacionalização. O Ministério da Saúde opta pela Saúde da Família como principal estratégia de intervenção no âmbito da APS. Estratégia cuja tendência, ao se contrapor àquela baseada na segmentação e na especialização da prática profissional, demonstra significativo potencial para resgatar a essência que caracteriza a relação profissional-usuário, a qual não se baseia apenas na técnica, mas em todo o processo comunicativo que se estabelece no ato desse encontro ${ }^{3}$.

Desse modo, é possível pensar em uma assistência diferenciada, pautada na integralidade do sistema, conferindo resolutividade às demandas em dois espaços distintos colocados por Cecílio ${ }^{4}$ como micro e macro, que se distinguem e se complementam para o avanço e a ampliação do acesso aos serviços de saúde.

Assim, entende-se acesso à saúde em sua dimensão sócio-organizacional da assistência, na qual os espaços criados nos serviços fundamentem-se no acolhimento das demandas e necessidades dos usuários; que os cuidados dispensados ao longo do tempo tenham continuidade e vínculo e favoreçam a coordenação de cuidados como prática que integra ações e serviços de saúde de forma resolutiva. Nessa perspectiva, considera-se que as posturas e estratégias adotadas pelos serviços de saúde garantam o acesso universal e equânime das pessoas, mediante adequada interpretação das demandas apresentadas, evidenciando as suas necessidades. Nessa ótica, favorece também a otimização da oferta ${ }^{1}$.

Cabe salientar que "a utilização dos serviços de saúde representa o centro do funcionamento dos sistemas de saúde, e os profissionais em grande parte definem o tipo e a intensidade de recursos consumidos para resolver os problemas de saúde" 2 .

Diante disso, também é necessário que os profissionais de saúde apropriem-se das particularidades do que venha a ser um acolhimento. Deve ser entendido em três sentidos que na verdade se integram: como postura, como técnica e como princípio de reorientação do trabalho. Postura assumida por todos os trabalhadores, representada na vontade de escutar, de entender e de tratar de forma solidária e humanizada a pessoa que busca o serviço de saúde. Técnica capaz de gerar ações e procedimentos organizados e interativos. Princípio orientador do trabalho que representa um projeto institucional que norteie todo o trabalho realizado pelo conjunto de atores envolvi$\operatorname{dos}^{5}$. Salienta-se que a acessibilidade traduzida na postura profissional deve ser aplicada em qualquer condição de uso dos serviços de saúde, sejam eles administrativos ou assistenciais ${ }^{2}$.

A escuta e o diálogo entre sujeito demandante e profissional de saúde, ocupam um lugar de relevância uma vez que possibilitam que essa intersubjetividade entre em ação, inserindo o usuário no espaço assistencial e conformando um 
movimento contra as práticas de fragmentação da assistência e objetivação dos sujeitos, concretizadas em ações mecanizadas e desumanas.

Destaca-se que a relação usuário-profissional é também fator preponderantemente importante para definir a utilização do acesso e a adesão ao tratamento. Esta relação deve estar assentada no processo de mudança do paradigma orientado pelo modelo cartesiano de atenção à saúde, transferindo o foco das atenções para a família e a comunidade. A reorientação dos serviços deve voltar-se na direção da saúde e não na doença, que apontem para a integralidade das ações.

Entende-se que a oferta de serviços deverá ser oportuna e adequada às necessidades da população, e não depender simplesmente da existência dos mesmos devido à imprevisibilidade dos eventos que ocorrem nos processos de saúdedoença. Faz-se necessário caracterizar a APS como a porta preferencial de entrada ao sistema visando o atendimento integral das necessidades de saúde dos usuários, de forma a garantir os princípios e as diretrizes do SUS, em busca da melhoria do acesso.

O estudo tem como objetivo analisar o acesso à atenção primária à saúde na perspectiva dos profissionais de equipes de saúde da família de três municípios do Estado de Minas Gerais.

\section{Metodologia}

Trata-se de um estudo de casos múltiplos com abordagem qualitativa. Os estudos de casos múltiplos apresentam a vantagem de que são considerados mais convincentes e mais robustos. Conta com a lógica da replicação, ou seja, após revelar uma descoberta significativa através de um experimento único, o objetivo imediato da pesquisa seria replicar essa descoberta conduzindo um segundo, um terceiro, ou até mais experimentos. A lógica do estudo de casos múltiplos deve seguir a partir da seleção de cada caso cuidadosamente, prevendo resultados semelhantes (replicação literal) ou de produzir resultados contrastantes por razões previsíveis (uma replicação teórica) ${ }^{6}$.

A abordagem qualitativa apresenta-se como uma possibilidade de escolha na qual o pesquisador lida com categorias analíticas e explicativas que extrapolam os dados quantitativos. Tais categorias são alcançadas na interface do teórico com o empírico, "na tentativa de colocar em evidência as possibilidades de interpretação dos fatos estudados e não exclusivamente demonstrar sua evidência."7.
O primeiro momento do percurso metodológico foi definir os municípios participantes do estudo. Foi definido como participantes da pesquisa um município de pequeno, um de médio e de grande porte contíguos, pautado na lógica de região de saúde. Foi então definido por conveniência os municípios de Ipatinga, Coronel Fabriciano e Santana do Paraíso que compõe a Região de saúde Macro Leste. Em seguida decidiu-se abordar uma Equipe de Saúde da Família (ESF) de cada município desses, de forma aleatória por meio de sorteio.

Os sujeitos da pesquisa ficaram estabelecidos como sendo um de cada categoria profissional que compõe oficialmente uma ESF segundo parâmetro do Ministério da Saúde, ou seja, enfermeiro, médico, auxiliar de enfermagem e agente comunitário de saúde; o quantitativo da amostra se deu a partir da saturação dos dados.

A amostra final totalizou 12 profissionais. $\mathrm{O}$ critério de inclusão para a escolha das equipes caso a unidade sorteada alocasse mais de uma ESF seria aquela com maior tempo de permanência dos profissionais, atribuindo ao elemento tempo, mais experiências, vivências e maior trajetória profissional na APS, na ESF relativos ao acesso.

Os dados foram coletados mediante realização de entrevistas semiestruturadas com trabalhadores de saúde alocados em Equipes de Saúde da Família. As entrevistas ocorreram individualmente, foram gravadas e em seguida transcritas, fundamentadas em um roteiro básico de perguntas para os profissionais.

A análise dos dados seguiu os passos de acordo com a proposta da análise de conteúdo, mais especificamente do tipo temática, quais são: ordenação dos dados após transcrição das fitas, leituras dos relatos buscando organizá-los para que possa ser formado um sentido para o conjunto de proposições; em seguida a leitura do texto com o objetivo de encontrar "unidades de significados" no discurso da pesquisa; transformação das unidades de significados em temas, interpretação dos temas e discussão com a literatura existente, e o relatório final que apresentará a compreensão realizada, sabendo que "o produto final é sempre provisório" ${ }^{\text {. }}$.

Foi apresentado o Termo de Consentimento Livre e Esclarecido (TCLE) em duas vias de igual teor assinado pelo pesquisador e entrevistado. Foi explanado aos participantes que a qualquer momento o mesmo poderia se desligar do estudo sem qualquer prejuízo de acordo com a Resolução no $196 / 96^{9}$ que garante o anonimato dos 
informantes no caso de pesquisas com envolvimento de seres humanos. A pesquisa foi aprovada pelo Comitê de Ética em Pesquisa da Universidade Federal de Minas Gerais e de acordo com as unidades de significado identificadas nos conteúdos foram determinadas duas categorias de análise para esse estudo: aspectos que compõem o perfil do profissional de saúde no acesso ao serviço de saúde e aspectos da organização do serviço para ampliação do acesso à saúde sob a ótica dos seus profissionais. Os profissionais foram identificados pelas iniciais de sua profissão seguida do número relativo à sequência de realização das entrevistas.

\section{Resultados e discussão}

O acesso à saúde deve contemplar desde questões de relações interpessoais até as sócio-organizacionais para favorecer a entrada das pessoas no sistema público de saúde. Para apresentar os conteúdos das entrevistas com os profissionais foram construídos dois blocos de discussões, sendo um relacionado a aspecto que compõem o processo de trabalho dos profissionais da APS e outro referente ao acesso e seus aspectos organizacionais na APS.

\section{Aspectos que compõem o processo de trabalho dos profissionais da APS}

Os 12 profissionais entrevistados se caracterizaram por seis de nível superior e seis de nível médio.

Os profissionais enfermeiros e médicos são do sexo feminino, com tempo de permanência na Equipe de Saúde da Família (ESF) acima de um ano, com oito horas de trabalho diário e com atuação exclusiva na equipe, sem outros vínculos empregatícios. Quanto à formação, possuem em média de quatro a seis anos de conclusão do curso de graduação.

Dado relevante é sobre a formação específica para atuação na APS; a pesquisa revela que a maioria dos profissionais possui especialização em outras áreas tais como dermatologia, Unidade de Tratamento Intensivo (UTI), auditoria e um profissional sem curso de especialização, o que nos remete a pensar em pouco acumulo teórico filosófico em relação aos conteúdos necessários ao desenvolvimento e ao incremento do processo de trabalho e certo despreparo para perceber e lidar com as dinâmicas do cotidiano do serviço e as reais necessidades da comunida- de. Para além do foco nas ações curativas, que acabam por empobrecer as tomadas de decisão e resultados, outros caminhos precisam ser pensados e traçados, se fazendo mais efetivos e com possibilidades reais de serem percorridos. Os profissionais precisam ultrapassar o trivial postulado pelos serviços de APS e estabelecer novas ofertas de tecnologias para saúde que partam da compreensão do universo de determinantes sociais e sanitários que envolve uma comunidade.

Outro fator interessante é a prestação exclusiva de trabalho à ESF, o que possibilita um envolvimento maior por parte do profissional com o serviço e com a realidade em que está inserido, tendo a possibilidade de se envolver mais profundamente nos problemas de seu território e população adscrita na busca de caminhos e soluções mais efetivos, e no enfrentamento aos desafios revelados no cotidiano de trabalho e na interpretação da panorâmica da comunidade com mais propriedade.

Travassos e Martins ${ }^{2}$ mencionam em seu estudo sobre Os conceitos de acesso a relação existente entre a utilização dos serviços de saúde e os prestadores de saúde, no que tange ao tempo de formação profissional, perfil demográfico (idade e sexo), especialidade que possuem, experiência profissional e condições psíquicas perante os enfrentamentos do cotidiano de um serviço de saúde pública, que determina a relação entre oferta e demanda.

Quanto aos agentes comunitários de saúde e auxiliares de enfermagem entrevistados são em sua maioria do sexo feminino, com vínculo empregatício exclusivo na ESF e com tempo médio de permanência superior a quatro anos. Percebeu-se que, se por um lado esses profissionais possuem dedicação exclusiva à sua equipe, por outro não possuem formação específica para atuarem na área e por isso não estão completamente sensíveis aos desafios do SUS e às reais necessidades da comunidade contribuindo para ampliação do acesso ao serviço de saúde. Alguns relatos dos profissionais endossam o comentário:

Bom eu chego na unidade eu atendo as urgências e emergências e o que tem na agenda já programada. [Faço] promoção, prevenção e eu oriento, na verdade na consulta em geral (AE 2).

Eu chego aqui organizo meus papeis e saio para visita domiciliar. A gente entrega exame, faz visita, a gente... fica... na reunião de hiperdia tudo a gente faz. [Entrega] convite pra hipertenso, convite pra puericultura, tudo a gente faz (ACS 2).

Para Figueiredo et al. ${ }^{10}$, o acesso depende ao mesmo tempo da combinação de recursos hu- 
manos e físicos disponíveis e dos sistemas administrativos e financeiros que determinam quais indivíduos receberão os serviços e em que condições. Deste modo, o acesso está associado a fatores como: tipo de atenção requerida a partir da necessidade do usuário, critérios de acesso e ingresso, alocação de mão-de-obra, distância, horário de funcionamento e qualidade do atendimento. Logo, o acesso é um importante indicador de impacto da atenção primária à saúde e avaliar em que medida este componente vem sendo alcançado constituiu-se uma fundamental ferramenta de aprimoramento do Sistema Único de Saúde.

A longa permanência na ESF não se traduz em movimentos no cotidiano capazes de modificar a realidade dos serviços de saúde no sentido da ampliação do acesso, contudo é importante para a construção de vínculo e longitudinalidade das ações, porém, como característica isolada se torna frágil na execução da promoção da saúde da população, conforme demonstrado nos relatos a seguir:

Chego às sete horas; após iniciar o sistema eu começo [a] fazer o acolhimento pelos pacientes que chegam inicialmente por ordem de prioridade, seria a... as urgências, vamos dizer assim, a pessoa que esta mais necessitada; não havendo isso é feito por idade (AE 1).

Eu trabalho de sete as dezesseis sou técnica do PSF, na parte da manhã eu fico por conta de visita domiciliar e na parte da tarde eu desenvolvo as demais atividades do dia a dia dentro da unidade, faço curativos, faço aferição de PA, glicemia, orientações, agendo consulta também pra médica (AE 3).

Nesse caso trata-se do espaço micro definido por Cecílio ${ }^{11}$ como sendo, o espaço singular de cada serviço, no qual a integralidade consiste num esforço conjunto (de toda a equipe) de compreender, captar, da melhor forma possível, as necessidades de saúde da população que procura o serviço. Souza ${ }^{12}$ comenta que acesso seria a inter-relação estabelecida entre os indivíduos, famílias e comunidades, gestores e equipe de saúde com construção de vínculo e laços de compromissos, num exercício permanente de geração de oportunidades e capacidades entre os sujeitos.

De um modo geral os profissionais médicos afirmaram se manterem presos às consultas ambulatoriais e às demandas espontâneas e programadas do dia, o que torna a prática de um profissional generalista incipiente frente as reais necessidades da comunidade e quanto à lógica de desenvolvimento do trabalho. Além disso, re- metem uma capacidade limitada na tomada de decisão e de governança para se posicionar com maior autonomia, dispositivo fundamental para construção e legitimação do trabalho.

Os enfermeiros demonstraram mais flexibilidade na execução do trabalho e compreensão das necessidades das demandas, fazendo atendimentos coletivos, individuais, dentro e fora das unidades de saúde.

Bom a gente começa as sete [horas], normalmente a gente faz [atende] demanda espontânea de manhã e os programas a gente concentra mais na parte da tarde, basicamente é isso. A promoção da saúde eu acho que é eficiente, isso quando a gente consegue ter um bom número de pessoas pra isso, porque nem sempre agente consegue trazer pra unidade aquele grupo que a gente deseja; a gente atinge mais ou menos $50 \%$ da nossa população alvo, pra trabalhar com prevenção $[O$ serviço tem] alta resolutividade porque a gente tem um médico que trabalha para o PSF [e que] não trabalha em outro local, então ele não tem que chegar atrasado, nem que sair mais cedo (E 3 ).

A organização do meu trabalho em si... como eu sou muito presa há um consultório, não tem muito que organizar né?! Veja bem, eu obedeço a uma agenda pré-estabelecida, a não ser no dia de demanda espontânea, fora isso, eu estou dentro do consultório. Se eu tivesse é... saídas do posto de saúde, da unidade... teria que me organizar...o que seria o ideal. Eu organizo grupos pra ver as demandas que tem na equipe, mas eu já não tenho tempo mais [de participar] (M1).

Os profissionais de nível médio de forma unânime demonstraram o desenvolvimento de um trabalho mecanicista, muitas vezes repetitivo, com pouca criatividade e baixa capacidade de impacto. Contudo apresentam um discurso de comprometimento com a execução do trabalho, e vontade de avançar na qualidade do serviço prestado, mas com certa alienação. Esse fator corrobora para a exaustão dos movimentos dos profissionais de saúde em seus serviços na construção dos processos de trabalho, sendo incapazes de traduzir aos olhos dos usuários a oferta de assistência de qualidade e processos terapêuticos consistentes e efetivos em respostas às demandas dessas comunidades.

É necessário ultrapassar para além das ações curativistas e tarefeiras, e vislumbrar caminhos mais efetivos a serem traçados e percorridos pelo conjunto de profissionais, a partir da compreensão do universo de determinantes sociais e de saúde que envolve um território e sua população, avançando no sentido da construção de proces- 
sos de trabalho mais efetivos, que fomentem a promoção da saúde entendida como mecanismo para a preservação da saúde desses indivíduos.

Faço encaminhamento para enfermeira com a solicitação do indivíduo e orientação, faço curativo, medicamento via oral, via $E V$, puericultura e a visita domiciliar (AE 2).

A organização do meu trabalho pelo fato que já tem muitos anos fazendo o mesmo serviço então já tem tudo programado; na parte da manhã fico por conta das visitas domiciliares então as meninas nem contam comigo aqui dentro da unidade e na parte da tarde o que tiver pra fazer a gente tá ali fazendo (AE 1).

Para a ocorrência de transformações em sistemas de saúde, em grande parte se realiza como consequência não apenas de políticas de saúde, mas de processos relativamente autônomos, tais como a racionalização funcional da atenção à saúde e mudanças de concepções dominantes sobre os processos de saúde/doença, processo de trabalho e de atenção à saúde ${ }^{13}$. Entende-se que a acessibilidade institucional é a capacidade de demonstrar zelo, dedicação, responsabilidade e envolvimento dos profissionais com o suprimento das necessidades humanas básicas das pessoas cuidadas ${ }^{14}$.

No conceito de acesso estão embutidos elementos como, presença física de recursos, eficácia ou resistência na capacidade de produzir os serviços do lado de quem planeja, mas também há, do lado daqueles para quem os serviços são criados e idealizados, a capacidade de reconhecer os obstáculos e avaliar os serviços, como refletiram Cohn et al. ${ }^{15}$.

Por outro lado, proximidade somente pode não ser elemento facilitador do acesso, pois, segundo Starfield ${ }^{1}$, outros fatores estão ali imbuídos, tais como informação, qualidade do atendimento, identificação da clientela com o serviço, como também algumas resistências colocadas pelo próprio serviço.

Quanto à integração da equipe todos os profissionais das diferentes categorias afirmaram positivamente sobre o relacionamento interpessoal e a capacidade de interação entre eles para execução e organização do trabalho diário, demonstrando satisfação em falar da relação construída por eles ao longo do tempo, entendida como facilitador e estimulador das práticas cotidianas de trabalho. Alguns dos entrevistados apresentaram como ponto forte do acesso o desenvolvimento de ações baseadas no diálogo entre equipe de saúde e comunidade, nesse estudo denominado "acolhimento", mas não conseguem traduzir o trabalho vivo em fomento da promoção da saúde, resultando em uma produção cotidiana sem muito impacto no que tange a ampliação do acesso à saúde e melhoria na resolutividade do serviço.

A equipe de trabalho aqui do PSF é muito boa, é como se fosse uma família, nós trabalhamos juntos, é uma procurando ajudar a outra, sabe, somos muito gratos a nossa enfermeira, que nos dá muito apoio, muita liberdade da gente expor os problemas pra ela né, trabalhamos também com a doutora que é uma médica ótima né. Então a nossa equipe de trabalho é como se fosse uma família (ACS 2).

Eu tento usar todos os recursos que a gente tem, a consulta médica, os agentes, os familiares, os serviços secundários, terciários se for necessário né... assistência social, conselho tutelar, então tudo aquilo que eu vejo de acordo com cada caso, que vai precisar de uma parceria específica; eu busco isso e na maioria das vezes eu discuto com a médica, com a equipe, $e$ as vezes eu também interajo com o supervisor da unidade, ele me ajuda a resolver os casos, a própria secretaria, com os coordenadores, gestores, então a gente resolve é dependendo da situação a gente vê o que vai ser necessário e corre atrás daquilo pra resolver o problema do paciente (E 2).

O diálogo e o intercâmbio de saberes técnicocientíficos e populares entre profissionais e usuários, podem construir, de forma compartilhada, um conceito sobre o processo saúde-doença, circunstância esta que apresenta uma relação dialógica, a qual proporciona mudanças duradouras de hábitos e de comportamentos saudáveis, visto serem ocasionados não pela persuasão ou autoridade do profissional, mas pela construção de novos sentidos e significados individuais e coletivos sobre o processo saúde-doença-cuidado ${ }^{16}$.

Pouca capacidade de tomar decisões e de visualizar problemas e suas possíveis soluções foram características identificadas nos relatos, acompanhado de discursos vagos e superficiais em alguns momentos, o que demonstra pouco envolvimento desses profissionais frente aos desafios postulados no acesso à saúde. Uma das auxiliares de enfermagem entrevistadas, alocada há sete anos na mesma equipe de saúde da família relatou o seguinte, quando abordada sobre a resolutividade do serviço:

Tem algumas falhas [no acesso]... mais o que a gente pode fazer a gente faz. Poderia ser melhor eu acho que é um pouco lenta ainda... mais ainda tá encaminhando. Em relação ao serviço tá resolvendo na medida do possível, claro que nem tudo 
a gente consegue resolvê o que a gente não consegue ai encaminha pra outro lugar (AE 2).

Os agentes comunitários de saúde participantes do estudo mencionaram sobre a resolutividade do acesso:

Olha nem sempre [que] a gente vai na casa de uma paciente encontra o problema e consegue resolver [o problema], a gente traz pra aqui na unidade e nem sempre aqui também é o caso de [ser] resolvido, as vezes leva pra secretaria e demora muito muito tempo, então nem sempre resolve, as vezes resolve... mas demora (ACS 2).

Pensar as necessidades de saúde significa um exercício de grande monta, pois seu (re)conhecimento sugere que se deva entrar em campos pedregosos, refratados por um conjunto de significados (social, político, ético e subjetivo) pouco explorados no cotidiano da gestão e da produção do cuidado em saúde, principalmente pelos profissionais ${ }^{3}$.

\section{Acesso e seus aspectos organizacionais na APS}

A Atenção Primária à Saúde (APS) é o meio pelo qual as duas metas de um sistema nacional de saúde - otimização da saúde e equidade na distribuição de recursos - se equilibram. Define a APS como o primeiro nível de assistência dentro do sistema de saúde, caracterizando-se, principalmente, pela continuidade e integralidade da atenção, além da coordenação da assistência dentro do próprio sistema, da atenção centrada na família, da orientação comunitária das ações e da competência cultural dos profissionais. São atributos na APS o acesso de primeiro contato, do indivíduo com o sistema de saúde, a continuidade e a integralidade da atenção e a coordenação da atenção dentro do sistema, atenção à saúde centrada na família, a orientação comunitária e a competência cultural ${ }^{1}$.

Travassos e Martins ${ }^{2}$, em artigo de revisão sobre os conceitos de acesso, advertem-nos que este é um conceito complexo, geralmente empregado de forma imprecisa e que muda ao longo do tempo e de acordo com o contexto. Mostram que a utilização dos serviços de saúde representa o centro do funcionamento do sistema e, embora com divergências conceituais e ideológicas, tem predominado a visão de acesso relacionado às características da oferta de serviço, ou seja, o uso de serviços é a sua própria expressão.

Ao se pensar o acesso a políticas públicas no SUS, faz-se necessário identificar o nível de (re)conhecimento dos vários atores que com- põem essa sociedade em relação à compreensão e à assimilação dos seus direitos (sociais, civis e políticos), e isso afeta as formas e as possibilidades de como a cidadania se enraíza nas práticas sociais $^{17}$.

A garantia de acesso aos serviços de saúde no Brasil está assegurada tomando como referência a aplicação cotidiana dos princípios organizativos e doutrinários do SUS, a partir da corresponsabilidade e da solidariedade dos entes federados, dos gestores, dos trabalhadores e dos usuários. Neste processo, vem ganhando destaque o poder local representado pelo município, pelas redes e teias de conexões que vão se formando ao organizar os serviços de saúde em suas várias complexidades, notadamente na atenção primaria à saúde (APS), em particular com a $\mathrm{ESF}^{17}$.

O acesso organizacional, conforme definido por Fekete ${ }^{18}$, envolve o modo de organização dos recursos de atenção à saúde. O qual refere-se a obstáculos internos (demora, na obtenção da consulta, tipo de marcação e horário, turnos de funcionamento, forma de organização dos processos de trabalho, vínculo, acolhimento); obstáculos externos (demora na espera pelo atendimento, demora para exames laboratoriais); e continuidade da atenção (incluindo mecanismos de referência e contra-referência).

Aqui o espaço a ser discutido se configura como o macro postulado por Cecílio ${ }^{11}$ como aquele que possui a capacidade de articulação do serviço de saúde a outros, constituindo uma rede muito mais complexa (intra ou intersetorial), pois a integralidade nunca se realiza em apenas um lugar, seja qual for a complexidade.

De um modo geral a organização dos serviços está vinculada à capacidade de gestão, o que confere planejamento, implementação e avaliação do serviço de saúde. Isso fica claro nas falas dos entrevistados, pois o estudo ocorre em três municípios distintos com consequente distinção na forma de gestão, o que se traduz nos relatos sobre organização do serviço, do próprio trabalho e da ESF em que estão inseridos. A organização das equipes, dos serviços e do próprio trabalho mencionado pela maior parte dos profissionais entrevistados, não demonstra avanços significativos capazes de romper os paradigmas postulados pela histórica hegemonia curativa e tecnológica. Para o desenvolvimento de um trabalho de qualidade é necessário estrutura, fluxos que sejam fixos e reconhecidos pela população, e pontos de atenção que se agreguem e articulem para dar continuidade e garantir a integralidade da assistência facilitando o acesso aos serviços e 
às tecnologias para saúde, impactando diretamente na qualidade de vida das pessoas. Vejamos os diferentes olhares sobre organização dos serviços de saúde a partir dos relatos de profissionais de saúde dos três municípios em tela.

Muitas vezes é mudado aquele fluxo sem a gente saber, quando a gente passa saber é devido ao próprio paciente que conta, entendeu? E quando a gente está tentando adaptar aquele fluxo, ele muda novamente, ou seja, muitos coordenadores pra um programa, são vários coordenadores e eles são muito é... separados, segregados, entendeu? Eles não tem é, uma união entre eles, então o que acontece muitas vezes você pega um coordenador de um programa de Hiperdia, por exemplo, ele não tem contato direto com a que faz a coordenação do Idoso por exemplo. Então o fluxo as vezes se esbarram, ai eles mudam [novamente], quando muda altera a rotina aqui em baixo, da base. A $i$ agente comunica, ai eles repensam, ai muda de novo, então atualmente tem um problema sério de coordenação nesse sentido, onde eles é... não fazem uma coordenação conjunta, quero dizer, deveria todos os coordenadores de programas atuarem ao mesmo tempo juntamente com o coordenador geral do PSF. E não acontece isso, então isso acaba que altera sim a organização do serviço (M1).

Eu acho a organização aqui muito boa, muito melhor que em vários outros municípios que eu já tive contato, porque principalmente por causa dessa relação de solicitar uma coisa [exames] e de ser atendido, eu acho que isso é mais importante às vezes pro paciente. Então assim eu acho que isso é mais importante pro paciente do que necessariamente fazer o exame, sabe, porque eu acho que resolve mais pra pessoa isso, essa boa comunicação da gente aqui com os responsáveis por jogar a coisa pra frente que é o pessoal da prefeitura, eu acho que é muito bom (M2).

$\mathrm{O}$ acesso significa o início do processo de resgate da cidadania e da responsabilidade individual; o não reconhecimento do direito distancia os sujeitos do seu papel de agente participativo na construção da cidadania ${ }^{19}$.

A superação de listas de espera não significa, apenas, aumento da oferta com mais intervenções, exames e procedimentos. Um ponto central que os elementos sistematizados neste trabalho permite sugerir é de que uma abordagem abrangente dessa problemática implica deslocar o foco da discussão do monitoramento de listas e/ou da ampliação da oferta para o da garantia de um acesso oportuno. Significa avançar na direção do monitoramento da qualidade dos sistemas de saúde de modo a enfrentar uma utilização de serviços pouco eficiente, uma vez que, em princípio, este é o diferencial que os sistemas orientados pela APS com redes integradas de serviços podem trazer. Implica, também, enfrentar o desafio político e a disputa de projetos tecno-assistenciais no difícil jogo da regulação em sistemas nos quais a doença se transformou em uma mercadoria altamente geradora de valor, discussão que é central para a sustentabilidade dos sistemas de saúde contemporâneo ${ }^{20}$.

Todavia, Donabedian ${ }^{21}$ menciona que para ter qualidade nos serviços de saúde é necessário considerar alguns elementos importantes denominados por ele como os "sete pilares" que seriam: a eficácia, entendida como o resultado do cuidado obtido na melhor situação possível; a efetividade, como o resultado do cuidado obtido na situação real; a eficiência, entendida da seguinte forma, se duas ações são eficazes e efetivas, a de menor custo será a mais eficiente; a otimização, onde o cuidado é relativizado quanto ao custo; a aceitabilidade que seria o quanto o cuidado se adapta aos desejos, expectativas e valores dos usuários; a legitimidade mencionada como a aceitabilidade do ponto de vista da sociedade, e, por fim, a equidade, entendida pelo autor como sendo o que é justo ou razoável na distribuição dos cuidados e de seus benefícios. Para se ter qualidade e consequente ampliação do acesso são necessárias uma gama de atributos que perpassam principalmente pela capacidade que o profissional desenvolve em avançar nesse processo e de capacidade de visualizar entraves e caminhos efetivos a serem construídos e percorridos.

Percebeu-se uma afinidade entre esses profissionais com o trabalho executado, porém pouca sensibilidade nos movimentos do cotidiano no que tange às necessidades reais da comunidade $\mathrm{e}$ identificação de seus verdadeiros problemas para uma construção coletiva que melhore o acesso e que transforme em efetividade de bem estar para a população. Quanto à educação continuada e permanente as mesmas são incapazes de produzir mudanças substanciais para a melhoria do acesso aos serviços de saúde pública, quando aplicadas isoladamente sem outros elementos relacionados à organização de rede de atenção a saúde.

Sobre as demandas mais prevalentes foram unânimes as relativas às doenças crônico-degenerativas como hipertensão arterial e diabetes mellitus, e referentes a crianças e adolescentes e saúde mental.

Criança tem muita, a gente tem o grupo de puericultura mais ai é até um ano, dois, depois disso 
fico meio que na consulta mesmo que tem muita criança... então eu acho que a procura maior é isso... e embora não tenha um psicólogo e psiquiatra eles vem consultar com problemas psicológicos com o médico clínico mesmo né. Então tem uma procura muito grande pra estas três coisas, os hipertesos, os diabéticos, as pessoas mais idosas, crianças, as gestantes e os problemas mentais demais. (E1).

Olha, o meu campo trabalho é um campo muito grande, o meu campo é um campo que tem muitos idosos, muitos hipertensos, muitos diabéticos. É há uma grande quantidade de usuários de drogas, né, adolescentes e grávidas, as maiores demandas são essas, hipertensos há maioria são hipertensos e diabéticos e são muitos idosos, existem muitas pessoas debilitadas, né, com dificuldade de vir à unidade de saúde. (ACS3).

Donabedian $^{21}$ define basicamente três componentes fundamentais para o avanço na qualidade assistencial. O primeiro se trata da estrutura, correspondente às características relativamente estáveis e necessárias ao processo assistencial, abrangendo área física, recursos humanos, recursos materiais e financeiros, sistemas de informação e instrumentos normativos (protocolos), apoio político e condições organizacionais. O componente processo corresponde à prestação da assistência segundo padrões técnico-científicos, estabelecidos e aceitos na comunidade científica sobre determinado assunto e a utilização dos recursos nos seus aspectos quanti-qualitativos. Inclui o reconhecimento de problemas, métodos diagnósticos, diagnóstico e os cuidados prestados, e o terceiro, resultados, que corresponde às consequências das atividades realizadas nos serviços de saúde, ou pelo profissional em termos de mudanças verificadas no estado de saúde dos pacientes, considerando também as mudanças relacionadas a conhecimentos e comportamentos, bem como a satisfação do usuário e do trabalhador ligada ao recebimento e à prestação dos cuidados, respectivamente.

Em relação aos fluxos relacionados aos níveis de atenção à saúde o usuário pode ser encaminhado ao serviço de referência, ao serviço de emergência ou ao Serviço de Atendimento Médico de Urgência (SAMU), após avaliação clínica na APS segundo a descrição dos profissionais quanto a rede de assistência a saúde. Também ocorre um fluxo interno, no qual médicos, enfermeiras, dentista, auxiliar de enfermagem e ACS se referenciam mutuamente de acordo com a necessidade do usuário.

De acordo com a necessidade encaminho pro serviço social, pro conselho tutelar, pro CEP que é o centro de especialidades, pra própria consulta médica aqui dentro da unidade, pra nutricionista, pro acompanhamento psicológico... é... no caso de necessidade de atenção secundária e terciária, vai ser encaminhada para os hospitais conveniados ao SUS, então assim a gente tem encaminhado de acordo com a necessidade pra todos os serviços que a gente tem, a gente recorre a todos os lados quando necessário. (E2).

Se for emergência, a gente vai tá encaminhando, ele vai tá sendo encaminhado para o Pronto Socorro, agora se não for emergência, a gente encaminha pra unidade de saúde ou orienta o usuário; porque dependendo da situação, talvez o usuário nem precisa procurar o posto, né... com uma simples orientação é resolvido o problema (ACS 3).

$\mathrm{O}$ acesso segundo a lógica de Andersen e New$\operatorname{man}^{22}$ deve ser considerado a partir de alguns dispositivos como aquisição de recursos adequados, o uso dos serviços de saúde e critérios de utilização, necessidades da população, e análise do território com características sociodemográficas e culturais bem definidas.

Um ponto central que os elementos sistematizados neste trabalho permitem sugerir é de que uma abordagem abrangente dessa problemática implica deslocar o foco da discussão do monitoramento de listas e/ou da ampliação da oferta para o da garantia de um acesso oportuno. Ou seja, significa avançar na direção do monitoramento da qualidade dos sistemas de saúde de modo a enfrentar uma utilização de serviços pouco eficiente, uma vez que, em princípio, este é o diferencial que os sistemas orientados pela APS com redes integradas de serviços podem trazer. Implica, também, enfrentar o desafio político e a disputa de projetos tecno-assistenciais no difícil jogo da regulação em sistemas nos quais a doença se transformou em uma mercadoria altamente geradora de valor, discussão que é central para a sustentabilidade dos sistemas de saúde contemporâneos ${ }^{20}$.

A qualidade do serviço de ser acessível é condição básica para que qualquer política pública, destinada a responder a qualquer necessidade social, alcance seus objetivos e impacte positivamente sobre o objeto de sua intervenção. No caso da política de saúde, em particular, a questão do acesso toma uma dimensão ruidosa, não apenas porque a legislação e as normas correspondentes enfatizam-no como elemento essencial ao desempenho do Sistema, nem do fato de haver uma dívida social enorme neste campo, mas, sobretudo, porque o "acesso à saúde" envolve dimen- 
sões complexas, face à complexidade das necessidades humanas, e à forma como tais necessidades se apresentam aos serviços de saúde ${ }^{3}$.

\section{Considerações finais}

Conhecer o olhar dos profissionais que atuam na APS se apresenta como um elemento importante na elaboração de ações de melhoraria do acesso aos serviços de saúde, com mais informação e alcance às tecnologias. Na perspectiva do acesso consideramos que as circunstâncias deparadas neste estudo se constituem como casos típicos dos diferentes territórios brasileiros frente a outras pesquisas consultadas.

$\mathrm{O}$ acesso aqui mediado pelo processo de trabalho dos profissionais da Atenção Primária e organização dos serviços se traduz em um formato ainda prescritivo, excludente e pouco participativo em como fazer saúde. Constitui-se através das falas dos próprios profissionais que o operam como serviços muitas vezes com pouca organização, com certa morosidade em relação às respostas às reais demandas da comunidade. Os serviços ofertados são focalizados e seletivos para responder a uma parcela da comunidade, e voltados a uma determinada queixa, sendo apontados tecnologicamente como escassos e distantes.

Ainda que haja processos instituintes, capazes de criar espaços de construção de práticas alternativas ao modelo dominante, como é o caso das Equipes de Saúde da Família, busca-se a possibilidade de ações humanizadas e acolhedoras junto aos usuários com um grau relativo de resolutividade na cadeia do sistema de saúde, eficiente o bastante para transformar a qualidade da assistência ofertada e que esteja ao alcance de todos.

Assim sendo, apesar do sistema de saúde em Ipatinga, Coronel Fabriciano e Santana do Paraíso serem considerados em dois desses municípios adequado, por parte dos entrevistados, foi mencionado em vários momentos das entrevistas as grandes demandas de atendimento que acabam por restringir o avanço nos resultados das equipes e dos serviços.
Além disso, os profissionais demonstraram acreditar que é possível melhorar as condições de trabalho e consequentemente da oferta de serviços a partir de uma clientela adscrita dentro dos parâmetros de territorialização definidos pelo Ministério da Saúde. O tipo de complexidade que é ofertado faz diferença no tempo de espera e na capacidade de resposta.

A escolha criteriosa do perfil dos profissionais, seja para inserção de novos ou mesmo para qualificação daqueles que já se encontram nos serviços, é preciso ser repensada para que haja a superação de certos movimentos do cotidiano de trabalho, como tomada de decisão, capacidade de governança dessas equipes e gestão do cuidado, que ultrapassem o modelo curativista hegemônico para que ocorra a ampliação do acesso e maior resolutividade dos casos. Fornecer mecanismos apropriados que facilitem o alcance aos diferentes níveis de atenção à saúde, como acolhimento e práticas mais humanizadas, que são tecnologias necessárias para a resolutividade dos casos.

Consideramos que se deva priorizar o emprego de medidas que apreendam cada uma das etapas no processo de utilização de serviços, de forma a permitir a verificação do efeito dos múltiplos fatores explicativos das variações no uso de serviços, como destas nas condições de saúde das pessoas e assim orientar de modo mais conducente a formulação de políticas para um melhor desempenho dos sistemas de saúde. Para tal é fundamental a construção de modelos teóricos que incorporem as particularidades de cada contexto a ser analisado, possibilitando um desenho real que contribua para a melhoria do acesso.

Ficou evidente que os municípios em tela possuem uma rede estruturada com pontos de atenção e bons equipamentos de saúde pública, desde as Equipes de Saúde da Família, que se apresentam como a porta preferencial de entrada ao sistema público de saúde, bem como, os serviços de média e alta complexidade que atendem através dos pontos de atenção existentes nessa região de saúde, porém é necessária uma reflexão sobre o valor de uso e o quanto tudo isso tem revertido em beneficio dessas comunidades. 


\section{Colaboradores}

SP Barbosa, CMM Penna e TS Elizeu participaram igualmente de todas as etapas de elaboração do artigo.

\section{Referências}

1. Starfield B. Atenção primária: equilíbrio entre necessidades de saúde, serviços e tecnologia. Brasília: Unesco, Ministério da Saúde; 2002.

2. Travassos CMR, Martins M. Uma revisão sobre os conceitos de acesso e utilização de serviços de saúde. Cad Saude Publica 2004; 20(Supl. 2):S190-S198.

3. Azevedo ALM. Acesso à atenção à saúde no SUS: o PSF como (estreita) porta de entrada [dissertação]. Recife (PE): Fundação Oswaldo Cruz; 2007.

4. Cecílio LCO. As Necessidades de Saúde como Conceito Estruturante na Luta Pela Integralidade e Equidade na Atenção em Saúde. In: Pinheiro R, Mattos RA. Os Sentidos da Integralidade na atenção e no cuidado à saúde. Rio de Janeiro: UERJ, IMS, ABRASCO; 2001. p. 113-126.

5. Silva Junior AG, Mascarenhas MTM. Avaliação da atenção básica em saúde sob a ótica da integralidade: aspectos conceituais e metodológicos. In: $\mathrm{Pi}$ nheiro R, Mattos RA, organizadores. Cuidado: as fronteiras da integralidade. Rio de Janeiro: CEPESCUERJ, Abrasco; 2005. p. 241-257.

6. Yin RK. Estudo de caso: planejamento e métodos. $3^{\mathrm{a}}$ Edição. Porto Alegre: Bookman; 2005.

7. Tittoni J, Jacques MG. Pesquisa. In: Jacques MG; Strey M, Bernardes N, Guareschi P, Carlos AS, Fonseca T, organizadores. Psicologia Social Contemporânea: livro-texto. Petrópolis: Vozes; 1998. p. 73-85.

8. Bardin L. Análise de Conteúdo. Lisboa: Edições 70; 2006.

9. Brasil. Ministério da Saúde (MS). Conselho Nacional de Saúde. Resolução nº 196 de 10 de outubro de 1996. Diretrizes e Normas Regulamentadoras de Pesquisas Envolvendo Seres Humanos. Diário Oficial da União 1996; 16 out.

10. Figueiredo TMRM, Villa TCS, Scatena LM, Gonzales RIC, Rufûno-Netto A, Nogueira JA, Oliveira AR, Almeida SA. Desempenho da atenção básica no controle da tuberculose. Rev Saude Publica 2009; 43(5):825-831.

11. Cecilio LCO. As necessidades de saúde como conceito estruturante na luta pela integralidade e equidade na atenção em saúde. In: Pinheiro R, Mattos RA, organizadores. Os Sentidos da Integralidade na atenção e no cuidado à saúde. Rio de Janeiro: UERJ, IMS, Abrasco; 2001. p. 113-126.

12. Souza MF. Programa Saúde da Família no Brasil: análise da desigualdade no acesso à Atenção Básica. Brasília: UnB; 2007.
13. Van Stralen CJ, Belisário SA, van Stralen TBS, Lima ÂMD, Massote AW, Oliveira CL. Percepção dos usuários e profissionais de saúde sobre atenção básica: comparação entre unidades com e sem saúde da família na Região Centro-Oeste do Brasil. Cad Saude Publica 2008; 24(1):148-158.

14. Pianucci A. Saber cuidar: procedimentos básicos em enfermagem. 4a Edição. São Paulo: SENAC; 2004.

15. Cohn A, Nunes E, Jacobi PR, Karsch US. A saúde como direito e como serviço. $3^{\text {a }}$ Edição. São Paulo: Cortez; 2002.

16. Alves VS. Um modelo de educação em saúde para o Programa Saúde da Família: pela integralidade da atenção e reorientação do modelo assistencial. Interface (Botucatu) 2005; 9(16):39-52.

17. Schwartz TD, Ferreira JTB, Maciel ELN, Lima RCD. Estratégia Saúde da Família: avaliando o acesso ao SUS a partir da percepção dos usuários da Unidade de Saúde de Resistência, na região de São Pedro, no município de Vitória (ES). Cien Saude Colet 2010; 15(4):2145-2154.

18. Fekete MC. Estudo da acessibilidade na avaliação dos serviços de saúde. In: Brasil, Organização PanAmericana da Saúde, Representação da OPAS no Brasil. Programa de Desenvolvimento de Recursos Humanos. Desenvolvimento gerencial de Unidades Básicas de Saúde do distrito sanitário: Projeto GERUS. Brasília: Ministério da Saúde, FNS, OPAS; 1995.

19. Brehmer LCF, Verdi M. Acolhimento na Atenção Básica: reflexões éticas sobre a Atenção à Saúde dos usuários. Cien Saude Colet 2010; 15(3):3569-3578.

20. Conill EM, Giovanella L, Almeida PF. Listas de espera em sistemas públicos: da expansão da oferta para um acesso oportuno? Considerações a partir do Sistema Nacional de Saúde espanhol. Cien Saude Colet 2011; 16(6):2783-2794.

21. Donabedian A. The seven pillars of quality. Arch Pathol Lab Med 1990; 114(11):1115-1118.

22. Andersen R, Newman JF. Societal and individual determinants of medical care utilization in the United States. Milbank Mem Fund Q Health Soc 1973; 51(1):95-124.

Artigo apresentado em 10/09/2012

Aprovado em 03/11/2012

Versão final apresentada em 23/11/2012 
